\title{
Predictions on the Development Dimensions of Provincial Tourism Discipline Based on the Artificial Neural Network BP Model
}

\author{
Yang Yang ${ }^{1,2}$, Jun $\mathrm{Hu}^{2}$, Yingchun $\mathrm{Lv}^{2} \& \mathrm{Mu} \mathrm{Zhang}^{2}$ \\ ${ }^{1}$ School of Management, Jinan University, Guangzhou, China \\ ${ }^{2}$ Shenzhen Tourism College, Jinan University, Shenzhen, China \\ Correspondence: $\mathrm{Mu}$ Zhang, Shenzhen Tourism College, Jinan University, Overseas Chinese Town, Nanshan \\ District, Shenzhen, 518053, China. Tel: 86-755-2693-1865. E-mail: Zhangmu@163.com
}

\author{
Received: April 11, 2013 Accepted: April 22, 2013 Online Published: May 20, 2013 \\ doi:10.5539/hes.v3n3p13 URL: http://dx.doi.org/10.5539/hes.v3n3p13
}

\begin{abstract}
As the tourism industry has gradually become the strategic mainstay industry of the national economy, the scope of the tourism discipline has developed rigorously. This paper makes a predictive study on the development of the scope of Guangdong provincial tourism discipline based on the artificial neural network BP model in order to find out how the branch of tourism studies can better adapt to the development of the tourism industry. The research findings indicate that the BP model can be applied to the predictions of the scope of the tourism discipline and provide a quantitative basis for decision making with regard to the spatial layout and optimal allocation of the tourism discipline.
\end{abstract}

Keywords: artificial neural network, BP model, tourism discipline

\section{Introduction}

During the period of the Eleventh Five-Year Plan, the State Council clearly proposed to develop the tourism industry into the strategic pillar industry of the national economy and into a modern service industry more satisfactory to the people. The tourism industry has become an important part of the national strategy. In 2011, the number of people involving domestic travel reached 2.641billion with the income of 193.0539 billion yuan, an increase of 13.2 percent and 23.6 percent over the previous year respectively. The tourism consumption has played a significant role in the expansion of domestic demand. Meanwhile, the construction of tourism discipline and the training of tourism talents in the country have made great achievements. Tourism management has become an independent discipline of management science and equals to business management in status as a main discipline with its own subordinate disciplines, namely tourism management, hotel management and exhibition economy and management. Accordingly tourism talent system with the characteristics of tourism industry has also been fundamentally established. And various kinds of talents in line with the rapid development of tourism industry have gradually expanded. Till 2011, 1115 ordinary institutions of higher learning had set up undergraduate major in tourism colleges across the country, increased by 148 over that of the year 2010 with the number of undergraduates at school reaching 599.8 thousand. But compared with the rapid developing tourism industry, there still exists relatively huge gap with regard to the total talent number, the poor overall quality of the talents, the unequipped discipline system, and the inadequate support for tourism education. Therefore The Outline of Chinese Tourism Industry during the Twelfth Five-Year Development Plan pointed out that we should balance the building of the talents of the tourism industry under the guidance of the development demand of the tourism industry, improve the overall quality of tourism education, reinforce the construction of tourism discipline, and optimize the system and course design of the tourism major so as to promote the status of tourism discipline and cultivate the tourism talents meeting the market demand. Thus, it is particularly meaningful to explore the major factors influencing the development scale of tourism discipline and the quantitative predictions of these factors to properly control the scale development of tourism discipline.

\section{The Research Status Quo of Tourism Higher Education at Home and Abroad}

In general, foreign scholars' researches on tourism higher education mode mostly are demonstrative ones with the region as a unit. They own relatively broad research range, unique perspective and conclusions that are region-oriented and directive. Jafari founded Annals of Tourism Research in 1974. Ever since 1979, a special 
issue gets published every year summarizing the relations between tourism industry and tourism education, theories and methods. Greg Richards (1998) has constructed the network education system that is suitable for the development of the integration of European tourism industry based on European integration. Deirdre Kelley-Patterson and Christeen George (2001) has proposed that the tourism education should narrow the gap between the demand of the tourism industry and the students' self-positioning based on the psychological contract. Shalini Singh (1997) has differentiated tourism education and training in accordance with characteristics of India's society and economy and established an education mode suitable for the development of the tourism industry. Isaac Sindiga (1996) has analyzed that vocational education and industrial reform took place at the same time due to the huge inflow of tourists into Kenya.

China is in the midst of accelerating urbanization and higher education being popularized. The research on the discipline of tourism has also aroused attention. Shen Baojia (1997) has depicted his understanding and opinion as to the relationship between the construction of the tourism discipline and higher tourism education and other related issues. Wang Jian (2008) has pointed out several major problems occurred in the near thirty years' development history of China's tourism undertaking and higher tourism education and research, including tourism and higher tourism education, the construction of the tourism discipline system, the constitute of the tourism management major course system and the qualitative of higher tourism education, and based on which the author demonstrated his own views on these issues. As to the quantitative prediction of the development scale of higher education, at present there are mainly two research methods. The first one is to use the analysis method of time series (the method of trend extrapolation, moving average method, the exponential smoothing method, Markov chain probability analysis method, grey prediction method and BP neural network) to analyze the trend. The trend extrapolation is to use the absolute number or the relative number of the recruit students or the scale of the present students to extrapolate according to the time trend throughout the years, and the exponential smoothing method refers to the weighted prediction. The second one is predictive regression analysis method that studies the interrelationship between the random variables and the influencing factors, which makes use of the separately selected dependent variables and independent variables to make regression analysis and prediction of the education scale, i.e., after the factors influencing the enrolment scale of higher education are identified, an interpretative method is used to predict the enrolment scale of higher education.

Since the relationship between influencing factors such as the education resources allocation of the tourism discipline isn't just an easy linear one. Thus this article is prepared to adopt the BP model of the artificial neural network to predict the development scale of the tourism discipline. This method can fully approach any complicated non-linear relationship, can learn and adapt to the dynamic characteristics of severe uncertainty system, boasts enormous superiority in handling the real-time process that are demanding in real time and hard to describe with models or rules, obtain a lot of random incidents, severely non-linear relationship and many various types of input and output.

\section{BP Neural Network and Factors Influencing the Scale of Tourism Discipline}

\subsection{Artificial Neural Network}

Artificial neural network (ANN) is an information processing system simulating the animal's brain structure and functions, which is a highly complex nonlinear dynamic system. It has all the common features of the nonlinear system, for example, the neural network has the features of high dimensionality, extensive continuity between neurons, self-adaptability and self-integrity, etc., among which the processing ability of ANN includes two sides: (1) the storage ability, namely the amount of information that can be stored in a neural network with $\mathrm{N}$ number of neurons; (2) the calculating ability, namely the setting of an input to get another output, which is the process from input to output. As to a specific network, the main problem in calculation is a process of mapping, which will project a fixed problem into an optimal network to be found. The main contents in ANN include network connecting topology, the features of the neurons, and learning rules, etc. according to connecting topology, the neural network model can be of four kinds: forward network, feedback network, random neuron network, and competing neuron network. BP (Back Propagation) network is a typical forward network, also called feed-forward network.

\subsection{BP Neural Network Model}

The essence of BP neural network is the Multi-Layer Perceptron (MLP), whose learning calculation uses BP calculation, so it is called BP neural network. The BP neural network includes input layer, hidden layer and output layer with the overall connection between the layers, but no connection between the units on the same layer. The BP calculation lies in making use of the output error to estimate the error of the previous leading layer, which will in turn be used to estimate the error of still further layer. In this way, the error of all other layers can 
be obtained, thus a transfer process is formed from the error shown in the output side to the input side step by step along the opposite direction of the input signal transmission.

Figure 1 shows the structure of a typical three-layer BP neural network. BP neural network can be seen as a high non-linear reflecting from input to output, namely $F: R_{m} \rightarrow R_{n}, \quad Y=f(x)$. For sample set input, some mapping $g$ can be thought to exist between input $x_{i}\left(R_{m}\right)$ and output $y_{i}\left(R_{n}\right)$, making $g\left(x_{i}\right)=y_{i}, i=1,2, \cdots, p$. Now it requires a mapping $f$ to make $f$ a best approximation of $g$ in a sense (usually in the sense of least-squares).

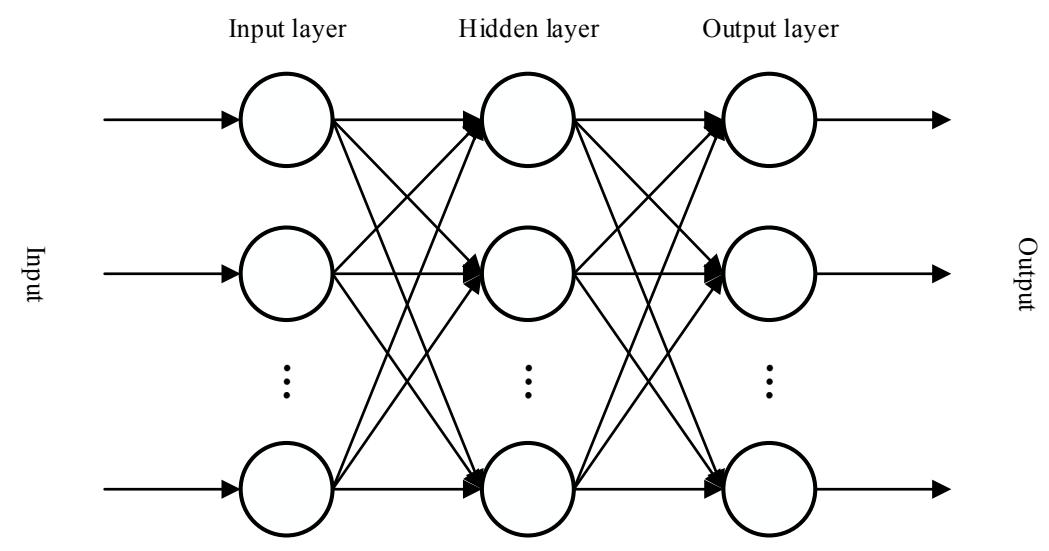

Figure 1. Three-layer neural network structure

\subsection{Major Factors that Influence the Scale of the Tourism Discipline}

The absolute number used in the predictions of the higher education scale generally means the enrollment scale or the scale of the students at school, specifically the scale of some discipline or major, and more often indicates the number of the students in this major at school, the author here chooses the student number of tourism colleges to represent the scale of the tourism discipline. But what incurs the change of the higher education scale is a shared result by many factors, and the influence of every factor varies in its extent in different periods. In the summary of the previous researches, there are several representative research paradigms as follows: (1) analyzing the relations between economic growth and higher education from the economic dimension; (2) studying the relations between political factors and higher education from political dimension; (3) analyzing the relations between cultural inheritance and development and higher education from cultural dimension; (4) analyzing the relations between demographic changes and higher education from demographic dimension. Speaking from what influences the scale of the tourism discipline, the authors have selected the following influencing factors given the features of the economy, the population, and the tourism discipline itself.

\subsubsection{Total Tourism Revenue}

The obvious influence of economic development on higher education has already become a generally accepted conclusion among all the influencing factors in research. Yan Quanzhi (2003) found that economy is the most fundamental, enduring influencing factor in his quantitative research in the relationship between higher education and economy; Sun Shaorong et al. (2004) used population-weighted method to do statistical regression of the enrolment rate of higher education around the world and GNP per capita, and he found the positive correlation tendency. Mao Hongtao and Ma Dan (2004) found that economic growth results in rapid development in higher education from the perspective of quantitative analysis. The development of tourism discipline is certainly influenced by the economic factor. The tourism revenue is an indicator of the general scale of the tourism industry and the comprehensive evaluation of the degree of development of a country or a region, which can well represent the level of the economic development of tourism industry, therefore the total tourism revenue is chosen as a variable for prediction.

\subsubsection{R\&D Expenditure of Higher Education Institutions}

R\&D expenditure includes direct spending for the activities of researching and developing projects and the whole expenditure indirectly used for the research and development activities. Lu Zuoqin and Xue Qingbo (1997) used the principal component analysis for the research of higher education, analyzing quantitatively some of the factors influencing the development of China's higher education, and the total sum of the expenditure of higher education is one of the variables. The scale of tourism discipline will not be promoted without the support of 
national policy funding. The support of some sum of funding is the precondition for the sustainable development of the discipline. The authors try to select the project spending associated with tourism discipline, but the volume involved being little, it isn't representative. Thus the relatively general spending for research and development of higher education institutions is chosen as a substitute.

\subsubsection{The Number of Students at School in General Universities Per 10,000}

The influence of population factor on higher education is becoming more and more obvious. Yu Peiguo et al. (2002) proposed the modeling model with regard to the economic level of development, population and the present demand of higher education with scientific, technological and cultural background, the result of which showed that population was an important influencing factor. The number of students at school in general universities per 10,000 can reflect the total number of students at school as an aspect of criteria, and as a part, the number of the students of tourism major will certainly tend to change as the number of the students at school in general universities per 10,000 changes.

\subsubsection{The Number of Tourism Colleges}

As a platform to train dedicatedly new talents with solid theoretical knowledge of the discipline needed in tourism industry, skills of the discipline, and creative spirits, the number of tourism colleges has direct links with the scale of tourism discipline. The subordinate majors under the tourism discipline will be established accordingly. Thus the number of tourism colleges is chosen as a variable of prediction in this study. The number of tourism colleges in this study refers to tourism higher education institutions and the tourism department (major) of general universities and adult higher education institutions for convenience of acquiring data.

In order to test whether these variables are mutually influencing, we have analyzed five variables for their correlation. Table 1 is the result reflecting their mutual relations. It can be seen that the correlation coefficients among the student number of tourism colleges, total tourism revenue, R\&D expenditure of higher education institutions, the number of tourism colleges and the number of students at school in general universities per 10,000 are all above 0.6 , which shows the existence of quite strong correlation among these variables and these variables can be chosen as the control variable in the prediction of the scale of tourism discipline

Table 1. The student number of tourism colleges in Guangdong Province and correlation coefficient of its affecting factors

\begin{tabular}{|c|c|c|c|c|c|c|}
\hline & & $\begin{array}{l}\text { Number } \\
\text { of } \\
\text { Student } \\
\text { in } \\
\text { Tourism } \\
\text { Colleges }\end{array}$ & $\begin{array}{l}\text { Total } \\
\text { Tourism } \\
\text { Revenue } \\
(100 \\
\text { Million } \\
\text { Yuan) } \\
\end{array}$ & $\begin{array}{c}\text { R\&D } \\
\text { Expenditure of } \\
\text { Higher } \\
\text { Education } \\
\text { Institutions (100 } \\
\text { Million Yuan) } \\
\end{array}$ & $\begin{array}{l}\text { The Number } \\
\text { of Students at } \\
\text { School in } \\
\text { General } \\
\text { Universities } \\
\text { Per } 10,000\end{array}$ & $\begin{array}{l}\text { The } \\
\text { Number } \\
\text { of tourism } \\
\text { colleges }\end{array}$ \\
\hline The Number of & Pearson correlation & 1 & $.677^{*}$ & $.615^{*}$ & $.845^{* *}$ & $.709^{*}$ \\
\hline Student in Tourism & Sig. & & .022 & .044 & .001 & .014 \\
\hline Colleges & $\mathrm{N}$ & 11 & 11 & 11 & 11 & 11 \\
\hline Total Tourism & Pearson correlation & $.677^{*}$ & 1 & $.992^{* *}$ & $.935^{* *}$ & $.901^{* *}$ \\
\hline Revenue (100 Million & Sig. & .022 & & .000 & .000 & .000 \\
\hline Yuan) & $\mathrm{N}$ & 11 & 11 & 11 & 11 & 11 \\
\hline R\&D Expenditure of & Pearson correlation & $.615^{*}$ & $.992^{* *}$ & 1 & $.911^{* *}$ & $.896^{* *}$ \\
\hline Higher Education & Sig. & .044 & .000 & & .000 & .000 \\
\hline $\begin{array}{l}\text { Institutions (100 } \\
\text { Million Yuan) }\end{array}$ & $\mathrm{N}$ & 11 & 11 & 11 & 11 & 11 \\
\hline The Number of & Pearson correlation & $.845^{* *}$ & $.935^{* *}$ & $.911^{* *}$ & 1 & $.925^{* *}$ \\
\hline Students at School in & Sig. & .001 & .000 & .000 & & .000 \\
\hline $\begin{array}{l}\text { General Universities } \\
\text { Per } 10,000\end{array}$ & $\mathrm{~N}$ & 11 & 11 & 11 & 11 & 11 \\
\hline \multirow{3}{*}{$\begin{array}{l}\text { The Number of } \\
\text { Tourism Colleges }\end{array}$} & Pearson correlation & $.709^{*}$ & $.901^{* *}$ & $.896^{* *}$ & $.925^{* *}$ & 1 \\
\hline & Sig. & .014 & .000 & .000 & .000 & \\
\hline & $\mathrm{N}$ & 11 & 11 & 11 & 11 & 11 \\
\hline
\end{tabular}




\section{Predictive Researches on the Scale of Tourism Discipline with BP Model}

\subsection{General Description of the Research Area}

As China's big province in economy and tourism, Guangdong's total tourism revenue increased from one billion yuan in 1978 to 483.527 billion yuan in 2011, an average annual increase of over 20 percent, and its foreign exchange revenue from tourism in 2011 reached $\$ 13.96$ billion, receiving 7.4934 million tourists from abroad, both ranking first across the country. The proportion of Guangdong Province's total tourism revenue in its whole economy in 2011 was over 9\%, making tourism industry gradually become the pillar industry, which played an important role of pushing the rapid development of Guangdong economy. Correspondingly, the scale of tourism discipline is constantly enlarging. Till 2010, there are 37 tourism institutions of higher learning and 37011 students of tourism colleges in Guangdong Province, ranking in the front row in the country respectively. Compared with other tourism provinces, tourism industry and the scale of tourism discipline of Guangdong Province are both representative to some extent, which can abundantly represent the evolution characteristics of the scale of tourism discipline as the tourism industry develops. Besides, the factors influencing the scale of tourism discipline are obvious and the data are easy to obtain, so Guangdong Province is chosen as the target of research in this study.

\subsection{Source of Sample Data}

Neural network model requires that the data should obtain easy availability, reliability and measurability. The authors select the data released by The Yearbook of China Tourism Statistics and Guangdong Province's Statistical Yearbook from 2000 to 2010. The specific data are shown in Table 2.

Table 2. The sample data of Guangdong province

\begin{tabular}{cccccc}
\hline Year & $\begin{array}{c}\text { Total Tourism } \\
\text { Revenue ( 100 } \\
\text { million Yuan })\end{array}$ & $\begin{array}{c}\text { R\&D Expenditure of Higher } \\
\text { Education Institutions }(100 \\
\text { million Yuan })\end{array}$ & $\begin{array}{c}\text { The Number of } \\
\text { Tourism } \\
\text { Colleges }\end{array}$ & $\begin{array}{c}\text { The Number of Students } \\
\text { at School in General } \\
\text { Universities Per 10,000 }\end{array}$ & $\begin{array}{c}\text { Number of } \\
\text { Students in }\end{array}$ \\
\hline 2000 & 1149.95 & 107.12 & 6 & 41.19 & 1736 \\
2001 & 1263.08 & 134.23 & 18 & 51.11 & 1796 \\
2002 & 1433.05 & 156.45 & 20 & 59.81 & 5257 \\
2003 & 1338.11 & 179.84 & 20 & 74.80 & 16094 \\
2004 & 1664.05 & 215.19 & 23 & 91.40 & 32815 \\
2005 & 1882.60 & 249.60 & 23 & 105.00 & 34958 \\
2006 & 2120.10 & 313.04 & 24 & 109.70 & 36390 \\
2007 & 2455.06 & 405.50 & 25 & 120.34 & 26666 \\
2008 & 2668.00 & 504.57 & 33 & 128.73 & 28006 \\
2009 & 3068.39 & 652.98 & 34 & 139.78 & 26233 \\
\hline
\end{tabular}

Data Source: 2000 2011 The Almanac of China Tourism Statistics and Guangdong Province's Statistical Almanac

After acquiring the sample data, because each index is mutually different, the order of magnitude of the original sample's data is greatly distinctive. For method of calculation and preventing partial neuron from getting saturated, this article normalizes the data between -1 and 1 , and uses premnmx function to quantify it under the command of MATLAB. After the preprocessed data training is completed, postmnmx function will be used to reverse the normalization of the output result for getting the actual value.

\subsection{BP Network Design}

BP neural network model of tourism discipline scale is created through invoking newff ( ) function in Matlab and the structure is as follows: network input layer that includes four neurons, such as total tourism revenue, R\&D expenditure of higher education institutions, the number of students at school in general universities per 10,000; a hidden layer, and the empirical formula that the number of the hidden layer's neurons usually adopts is:

$$
l=\sqrt{m+n}+\alpha
$$


$l$ represents the number of hidden nodes;

$m$ represents the number of input nodes;

$n$ represents the number of output nodes;

$\alpha$ represents the regulation constant, between 1 and 10 .

Finally, through comparison, it's found that when the number of hidden layer is 6 , network's convergence rate is relatively faster and the error is less, thus the unit number of the hidden layer is 6 and the output layer becomes one neuron, that is, the student number of tourism colleges. According to the general design plan, transfer function of the neuron in the middle layer is tansig function, and the transfer function of the hidden layer's neuron is purelin function, therefore the prediction model of the scale of tourism discipline that we finally get is 4-6-1, the training function is devised as traingdx function, network training target being 0.001 .

\subsection{Network Training and Prediction}

This article selects the data from 2000 to 2007 as the input data for engaging in network training, and the training result is showed in Figure 2. The accuracy of the network gets 9.92112e-006 after 316 times of learning. The data simulation training is also done, and the error target is found to be realized. Then we use the well-trained network to predict the data from 2008 to 2010, the result is shown by the following Table 3 . It can be seen that there exists much difference between the predictive value and the actual value, as the scale of the student number of tourism colleges diminishes in 2009 due to some reason with the occurrence of an inflection point that the network can't distinguish it well. However, the relative error of 2008 and 2010 is smaller with higher degree of fitting; generally speaking, the network has already possessed the capability of prediction. Therefore we can use this network to make predictions.

The number of training sample has much relevance with the training effect, in the meantime it indicates that the predictions of neural network aren't suitable for long-term predictions and all the data before next year must be input to predict the data of next year so as to optimize the learning effect. Network's standardizing capability is also closely linked with the number of data. Thus if the network design is proper, we should try our utmost to input the whole data of all the years before the year to be predicted into the network with the purpose of improving network's learning and standardizing capabilities. Therefore we input all the data between 2000 and 2010 into the well-trained network to study, and then we use its learning situation to predict the data of 2012-2015. The data of the influencing factors (the total revenue of tourism, the R\&D expenditure of higher education institutions, the number of students at school of general universities and tourism colleges per 10,000) 0f 2012-2015 are used to conduct predictions, we get the result that the number of students of Guangdong tourism college for 2012-2015 is 39261, 40126, 43673, and 45596 respectively.

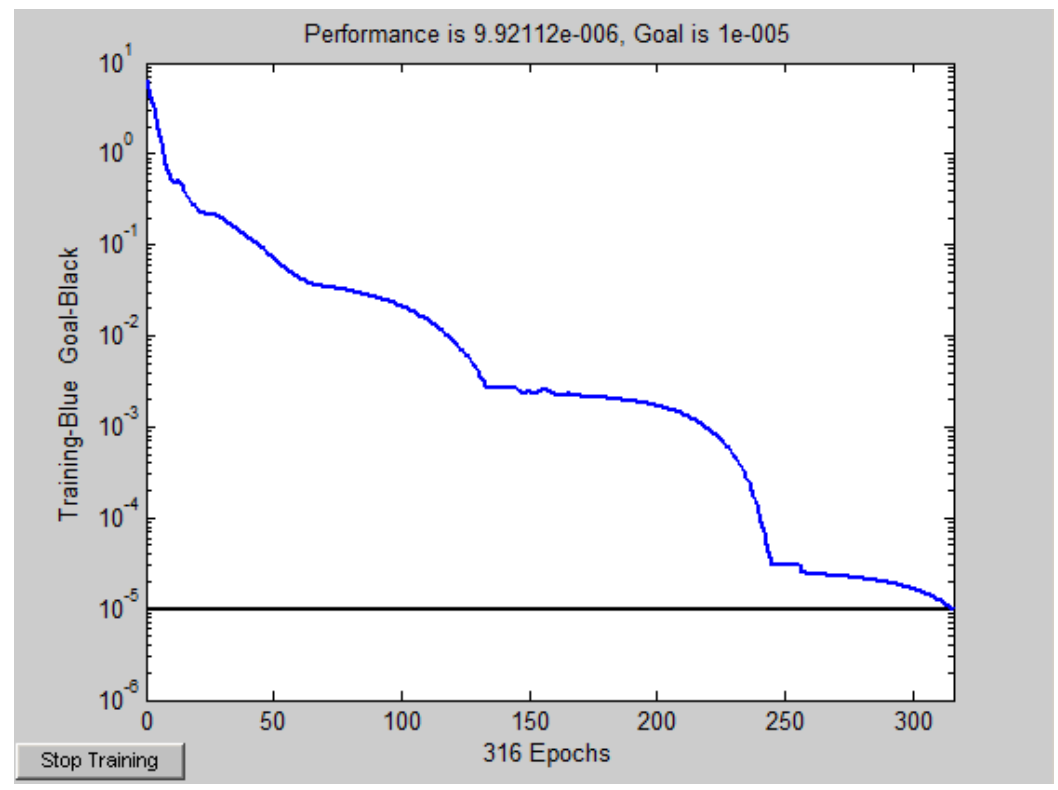

Figure 2. Neural network training process chart 
Table 3. The predictive value and error of the scale of tourism discipline of Guangdong from 2008 2010

\begin{tabular}{cccc}
\hline Year & Actual Value & Predictive Value & Relative Error \\
\hline 2008 & 28006 & 28137 & 0.00468 \\
2009 & 26233 & 29021 & 0.10628 \\
2010 & 37011 & 37369 & 0.00967 \\
\hline
\end{tabular}

\section{Conclusion}

On the basis of introducing the network structure of BP neural network and analyzing the major factors influencing the scale of tourism discipline, this article creates the prediction model of the scale of provincial tourism discipline based on artificial neural network BP model. A conclusion can be drawn as follows: the total revenue of tourism, the $R \& D$ expenditure, the number of students at school in general universities, and the number of tourism colleges have relatively strong correlation and can be used as a interpretative variable to predict the scale of tourism discipline in Guangdong Province. The case study of the sample data of Guangdong Province's tourism discipline proves that the output result matches the target result and the prediction rules of the scale of higher education, which offers a perspective and method for the prediction work of tourism discipline scale and meanwhile provides quantitative foundation for the policies for our country's tourism discipline in regard to its space layout and optimal allocation.

\section{Acknowledgements}

This work was supported by the Key project of the 11th Five-Year Planning of National Educational Science of Ministry of Education (DIA100305).

\section{References}

Kelley-Patterson, D., \& George, C. (2001). Securing graduate commitment: An exploration of the comparative expectations of placement students, graduate recruits and human resource managers within the hospitality, leisure and tourism industries. International Journal of Hospitality Management, 20(4), 311-323. http://dx.doi.org/10.1016/S0278-4319(01)00019-6

Lu, Z., \& Xue, Q. (1997). Principal Component Analysis of Factors Affecting Development of Higher Education. Journal of North China University of Technology, 9(1), 24-28.

Mao, H., \& Ma, D. (2004). The Quantitative Analysis of the Relationship of the Development of Higher Education and Economic Growth. Finance and Economics, 1, 92-95.

Mao, J. (2008). Assessment Method of Quantitative Prediction of the Scale of Higher Education. Heilongjiang Researches on Higher Education, 166(2), 9-12.

Mi, H., Wen, X., \& Zhou, Z. (2003). An Empirical Analysis of Demographic Elements and the Change of Scale of China Higher Education in the Future 20 Years. Population Research, 27(6), 76-81.

National Tourism Bureau. (2012). 2011 Statistical Bulletin of China's Tourism Industry. Retrieved from http://www.cnta.gov.cn/html/2012-10/2012-10-25-9-0-71726.html

Richards, G. (1998). A European network for tourism education. Tourism Management, 19(1), 1-4. http://dx.doi.org/10.1016/S0261-5177(97)00081-2

Shen, B. (1997). On the construction of tourism discipline and the tourism higher education. Tourism Tribune Supplemental Issue of Tourism Education, 8, 21-24.

Sindiga, I. (1996). Domestic tourism in Kenya. Annals of Tourism Research, 23(1), 19-31. http://dx.doi.org/10.1016/0160-7383(95)00040-2

Singh, S. (1997). Developing human resources for the tourism industry with reference to India. Tourism Management, 18(5), 299-306. http://dx.doi.org/10.1016/S0261-5177(97)00018-6

Sun, S., Zhang, W., \& Li, L. (2004). Research on the Relationship between Higher Education and Economic Development. Journal of Public Management, 3, 75-84.

The Statistic Bureau of Guangdong Province. (2012). Guangdong Almanac 2012. Retrieved from http://www.gdstats.gov.cn/tjnj/2012/c17.htm

Wang, J. (2008). On the Development of Tourism Discipline and the Building of Curricula System in the Major 
of Tourism Management. Tourism Tribune, 23(3), 19-23.

Yan, Q. (2003). Probe of Factors of Influence Exerted by Higher-Education Development. Theory and Practice of Education, 8, 13-15.

Yu, P., Yang, X., Shen, Y., \& Liao, B. (2002). The Higher Education Demand Forecasting and Scale Confirming of Our Country. Rorecasting, 21(3), 9-12.

Zhu, K., \& Wang, Z. (2010). Full knowledge of MATLAB neural network. Beijing: Electronics Industry Publishing House. http://dx.doi.org/10.1016/j.neunet.2010.08.001 